\title{
Research on Simulation and Field Measurement Technology \\ of Floor Mining Failure Depth
}

\author{
Wencheng Song ${ }^{1, a}$, Chunbo Zhao ${ }^{1, b}$, Guang $\mathrm{Li}^{1, \mathrm{c}}$, Donghui Wang ${ }^{1, \mathrm{~d}}$ \\ ${ }^{1}$ College of Mining and Safety Engineering, Shandong University of Science and Technology, Qingdao, Shandong, 266590, \\ China \\ aemail:skdkyswc@126.com, ${ }^{\mathrm{b}} 1249279787 @$ qq.com, ${ }^{\mathrm{c}} 38345280 @$ qq.com, ${ }^{\mathrm{d}}$ wdh19911204@163.com
}

\begin{abstract}
Aiming at the detection problem of floor mining failure zone after mining, in order to grasp the failure law of floor strata caused by mining and ensure the safe mining on confined water, in this paper, the methods of the theoretical prediction and FLAC ${ }^{3 D}$ numerical simulation was adopted to study floor mining failure depth of the $\mathbf{4 1 3 0 3}$ working face in Huafeng coal mine, and then the system of double ends borehole plugging device in measuring leakage was applied to the field measurement to verify the theoretical prediction and numerical simulation results, and the results of the three methods were compared. The research shows that: (1) the prediction depth of floor mining failure depth is $16.89 \sim 21.24 \mathrm{~mm}$, and the numerical simulation results are $15 \mathrm{~m}$, and the measured depth is $13.15 \mathrm{~m}$; (2) Through comparison, it can be seen that the numerical simulation result is basically close to the field measured result. The result of empirical formula is expected to be conservative. In summary, the maximum floor mining failure depth of the 41303 working face is $13.15 \mathrm{~m}$. It provides scientific basis for the safe mining of coal resources under the pressure of the confined water; (3) With the advancing of the 41303 working face, the plastic zone of the bottom plate is increasing. When the working surface reaches $90 \mathrm{~m}$, the depth of the floor mining failure reaches the maximum value of $15 \mathrm{~m}$, and the depth is no longer increased and its shape is a straight line which is approximately parallel to the floor. the change trend of plastic zone is consistent with the maximum principal stress.
\end{abstract}

Keywords - Floor Mining Failure Zone; Double Ends Borehole Plugging Device; Theoretical Prediction; FLAC ${ }^{3 \mathrm{D}}$; Field Measurement.

\section{I.INTRODUCTION}

After the coal seam mining, deformation and damage occurred in the floor strata because of the pressure of mine. And three damage zones which are similar to that in overlying strata are formed in floor strata. It is called "Three Underlying Belts". According to the extent of damage and fracture conductivity of three underlying belt from top to bottom, it were as follows: floor mining failure zone, complete rock zone and confined water conduction zone zone[1]. The study on the floor failure depth can not only reflect the characteristics of floor rock mass destruction caused by mining but also provide basic data for safety mining on confined water. It is of great importance to the prevention of mine water inrush disaster, reasonable arrangement of protective coal pillar, safety mining evaluation of coal resources. Many scholars have used theoretical analysis, similar material simulation, numerical analysis and field measurement to study the failure depth of floor rock mass and the development law of mining fracture, and have achieved fruitful results.

In the aspect of theory, Zuoyu Wang and Baiying Li put forward to the theory of "three zones", "in situ tension crack and zero position failure" and "thin plate", and study the damage depth and water inrush mechanism of floor rock mass[2-5]. According to the key strata theory of KS, Liangjie $\mathrm{Li}$ and Jian Sun discussed and analyzed the mechanism of water inrush from mine floor strata[6-7]. Aiming at the problem of floor mining failure, Longqing Shi put forward to the linear regression and nonlinear regression formula and used a large number of measured data to verify the formula, which has been proved to be of high value[8]. Considering the anisotropy of the floor rock mass deformation and strength, he studied the distribution law of mining stress and the failure depth of the floor rock mass [9].

In the aspect of similar material simulation, Jinan Wang used the full stress strain test and single crack permeability test on floor rock to study the fracture characteristics and seepage characteristics of rock mass, and further reveals the mechanism of fluid solid coupling in rock mass[10]. Taking floor rock mass on high confined water in Jiulong coal mine as back ground, Yaodong Jiang adopted the floor simulation device designed by himself to carry out the simulation experiment of similar materials to further explore the law of floor failure[11].

In the aspect of numerical analysis, Weitao Liu adopted the numerical software FLAC ${ }^{3 \mathrm{D}}$ to further study the main control factors of the stability and failure depth of the floor[12-14]. Rui Zhang used FLAC ${ }^{3 \mathrm{D}}$ to carry on the comprehensive test and the numerical simulation to the coal seam floor mining destruction characteristic[15].

In the aspect of field measurement, taking the actual 
project as the background, Weitao Liu applied double ends borehole plugging device to field measurement of floor failure depth[16]. After that, some scholars carried out the failure depth of floor detection research using microseismic monitoring technology[17] and acoustic wave CT technology[18-19].

In summary, the research methods of floor mining failure depth is varied, which has experienced the different stages of theoretical analysis, numerical simulation, similar material test and field test. By contrast, the field test results are the most reliable. The method of field measurement represented by "double ends borehole plugging device" has the advantages of simple operation, high accuracy and so on. Based on this, in the paper, taking the 41303 working face in Huafeng coal mine as background, the author has applied the theory prediction, numerical simulation FLAC ${ }^{3 \mathrm{D}}$ and the field measurement to study the failure depth of floor mining. The theoretical and numerical simulation results are consistent with the field measurement results, and it has achieved good application.

\section{II.ENGINEERING BACKGROUND}

The lower group coal in Huafeng coal mine is mainly mined by 13,15 and 16 coal seams. Its 41303 working face is located in the No.13 coal seam, the mining level is $-520 \mathrm{~m}$. The dip angle in this coal seam is 25 degrees $~ 35$ degrees, its average dip angle is 30 degrees, and the thickness of coal seam is $0 \sim 1.91 \mathrm{~m}$, its average thickness is $0.94 \mathrm{~m}$. The direct roof of the coal seam is fine sandstone, its average thickness is $5 \mathrm{~m}$, and the direct floor is medium sandstone, its average thickness is $2 \mathrm{~m}$. The composition and thickness of the roof and floor of the coal seam are shown in Figure 1.

\begin{tabular}{|c|c|c|c|}
\hline Column & Rock (coal) layer name & Thickness (m) & Characterization of rock strata \\
\hline $\begin{array}{ll}\cdot \cdot \cdot \cdot \\
\cdot \cdot \cdot \cdot\end{array}$ & Fine sandstone & 19 & $\begin{array}{l}\text { Gray white, fine - grained structure, the development of the top cracks, } \\
\text { mainly quartz, feldspar. }\end{array}$ \\
\hline $\begin{array}{ll}\cdot \cdot \cdot \cdot \\
\cdot \cdot \cdot \\
\end{array}$ & Mmedium sandstone & 4.2 & Gray white, fracture is not developed, local mudstone \\
\hline$\frac{\cdot \cdot \cdot}{-\cdot \cdot \cdot-}$ & Silty sandstone & 13 & Deep grey silty structure, middle and lower part of mud \\
\hline 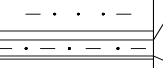 & Sandy mudstone & 2.5 & $\begin{array}{l}\text { Deep gray, layered structure, the upper visible calcite veins, the } \\
\text { bottom joint development, more broken }\end{array}$ \\
\hline & Fine sandstone & 5 & $\begin{array}{l}\text { Light grey, fine grained structure, medium thin layer, calcareous } \\
\text { cementation, joint and fissure development }\end{array}$ \\
\hline $\begin{array}{ll}\cdot \cdot \cdot \cdot \\
-\cdot \cdot \cdot-\end{array}$ & No.13 Coal Seam & 0.94 & Simple structure, average thickness of coal seam $0.94 \mathrm{~m}$ \\
\hline $\begin{array}{l}\cdot \cdot \cdot- \\
-\cdot \cdot \cdot-\end{array}$ & Mmedium sandstone & 2 & Grey white, medium coarse grained structure, calcareous ementation \\
\hline$-\cdot \cdot \cdot-$ & Fine sandstone & 4.5 & Deep grey sandy structure, locally with stone \\
\hline $\begin{array}{ll}\cdot \cdot \cdot \cdot \\
\cdot \cdot \cdot\end{array}$ & Silty sandstone & 25.5 & Gray, dark gray siltstone, layered core \\
\hline 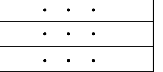 & Mmedium sandstone & 25 & $\begin{array}{l}\text { Gray white, medium coarse grained structure, medium and thick layered } \\
\text { structure of calcareous cementation, mainly contain quartz stone, feldspar }\end{array}$ \\
\hline $\begin{array}{ll}------ \\
------1\end{array}$ & Mudstone & 8 & $\begin{array}{l}\text { Contains Brown calcite gray component, containing mud and rock joints } \\
\text { is broken }\end{array}$ \\
\hline
\end{tabular}

Fig.1 Strata comprehensive histogram

The method of longwall mining on srtike was adopted to manage the roof in the working face. The strike and inclined length of the working face is $400 \mathrm{~m}$ and $150 \mathrm{~m}$, respectively. Its surrounding areas were not mining. Within the scope of the work face, there is no obvious fault and structure. Six small faults between $0.6 \sim 1.6 \mathrm{~m}$ were revealed in the tunneling process of the mining roadway. Near the top of the roof was broken, the coal seam was soft and easy to fall.

The Calculation index of physical and mechanical properties of rock strata selected by rock mechanical property test are shown in Table 1.

\section{III.THEORETICAL PREDICTION}

Referring to the geological conditions of the 41303 working face in Huafeng coal mine, according to the empirical formula of regulations of buildings, water, railway and main well lane leaving coal pillar and press coal mining, it can be expressed as follows:
If considering the mining depth, angle and inclined length of working face, the prediction formula for the depth of floor water-conductive fissure zone is that:

$$
h_{1}=0.0085 H+0.1665 \alpha+0.1079 L-4.3579
$$

In the type: $h_{1}$ stands for the depth of floor water-conductive fissure zone, its representative unit is meter; $H$ is mining depth; $\alpha$ is the dip angle of coal seam, its unit is angle; $L$ is inclined length of long wall working face.

If only considering the inclined length of the working face the prediction formula for the depth of floor water-conductive fissure zone is that:

$$
h_{1}=0.7007+0.1079 L
$$

In the type: $h_{1}$ stands for the depth of floor water-conductive fissure zone, its representative unit is meter; $L$ is inclined length of long wall working face. 
TABLE 1 Physical and mechanical properties calculation index of rock group

\begin{tabular}{|c|c|c|c|c|c|c|c|}
\hline Serial number & Lithology & Bulk density $/ \mathrm{kN} \cdot \mathrm{m}^{-3}$ & Elastic modulus/MPa & Poisson ratio & Cohesive force/MPa & $\begin{array}{l}\text { Friction } \\
\text { angle } /\left({ }^{\circ}\right) \\
\end{array}$ & $\begin{array}{c}\text { Tensile } \\
\text { strength/MPa }\end{array}$ \\
\hline 1 & Fine sandstone & 25.7 & 11000 & 0.17 & 7.38 & 29.9 & 1.06 \\
\hline 2 & Medium sand & 25 & 10000 & 0.2 & 6.28 & 28 & 1.04 \\
\hline 3 & Silty sandstone & 25.5 & 11000 & 0.2 & 1.26 & 28.5 & 0.84 \\
\hline 4 & Sandy mudstone & 25.1 & 10000 & 0.18 & 6.93 & 31 & 1.04 \\
\hline 5 & Fine sandstone & 26.2 & 10000 & 0.18 & 7.23 & 30.1 & 1.08 \\
\hline 6 & No.13 Coal Seam & 14 & 1300 & 0.24 & 1.04 & 23 & 0.04 \\
\hline 7 & Medium sand & 25.7 & 11000 & 0.21 & 6.32 & 29.8 & 1.03 \\
\hline 8 & Fine sandstone & 23 & 9900 & 0.19 & 5.85 & 28 & 1.06 \\
\hline 9 & Silty sandstone & 25.9 & 11000 & 0.19 & 6.25 & 32 & 0.82 \\
\hline 10 & Medium sand & 25.7 & 10000 & 0.21 & 6.27 & 29.5 & 0.97 \\
\hline 11 & Mudstone & 24.8 & 4000 & 0.25 & 1.22 & 31 & 0.41 \\
\hline
\end{tabular}

The depth of the mining induced damage zone based on the above formula (1) and (2) is 16.89 21.24m. Taking the possible abnormal situation such as local large floor mining failure depth into account, the maximum failure depth of the floor rock mass is predicted to be $21.24 \mathrm{~m}$.

Therefore, the extension height of the observation hole must be more than this value, and also need to extend the length of the drill hole $5 \sim 10 \mathrm{~m}$ in order to measure the non leaking hole section, regard it as the maximum boundary of controlling the depth of mining damage.

\section{IV.NUMERICAL SIMULATION}

\section{Model construction}

41303 working face mining geological model constructed according to the mining geological conditions, strata comprehensive histogram and physical and mechanical parameters of rock strata of research area in Huafeng coal mine is as shown in Figure 2.

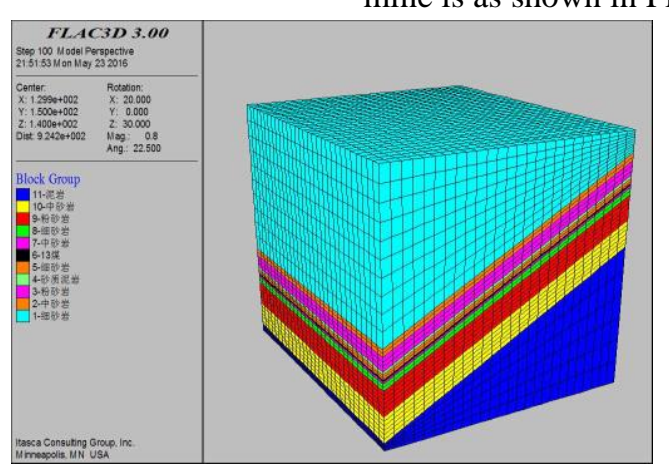

Fig.2 FLAC $^{3 \mathrm{D}}$ numerical model

Model size: Length is $260 \mathrm{~m}$, Width is $300 \mathrm{~m}$, Height is 280m;

Model boundary: The front and back boundaries and the left and right boundary of the model are constrained by the horizontal direction displacement; The upper boundary layer is simplified to $13 \mathrm{MPa}$ uniform load, and the bottom boundary is imposed with full constraint.

Mining area: From the direction of the working face length is $200 \mathrm{~m}$, inclined length is $150 \mathrm{~m}$, and the excavation height of the coal seam is $0.94 \mathrm{~m}$, excavation length along the strike of the coal seam at every step is $10 \mathrm{~m}$. Considering the boundary effect, mining start and stop line of working face from the left and right boundaries of the model is $75 \mathrm{~m}$; The width of roadway protection pillar before and after the model boundaries is respectively $50 \mathrm{~m}$.

\section{Simulation results and analysis}

With the working face mining, due to the influence of mining, deformation and cracks appear in the floor rock mass, and then the floor mining failure zone is formed. When the working face is pushed to the $40 \mathrm{~m}, 60 \mathrm{~m}, 80 \mathrm{~m}$ and $120 \mathrm{~m}$, the plastic zone and the maximum principal stress of floor rock mass affected by the mining along the inclined direction of the working face is shown in figure 3 to figure 6 . 


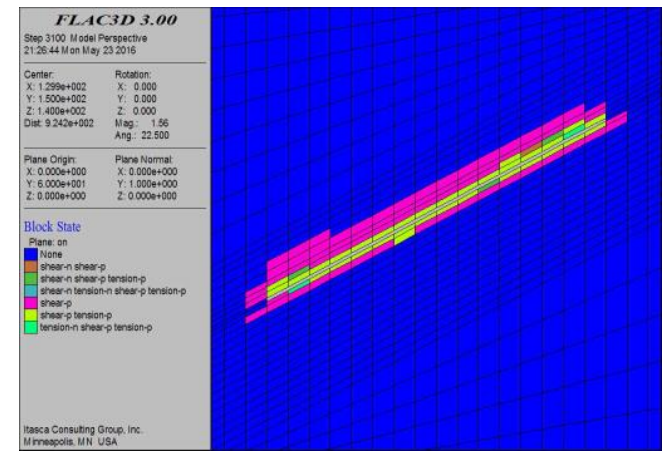

(a) The floor plastic zone

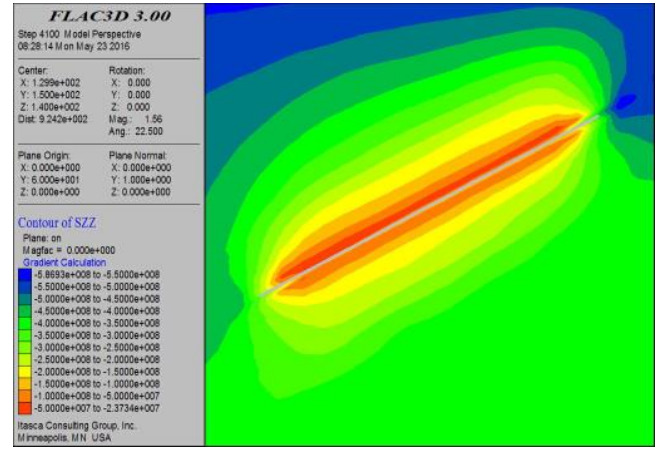

(b) The maximum principal stress

Fig.3 Distribution of plastic zone and maximum principal stress when mining 40m

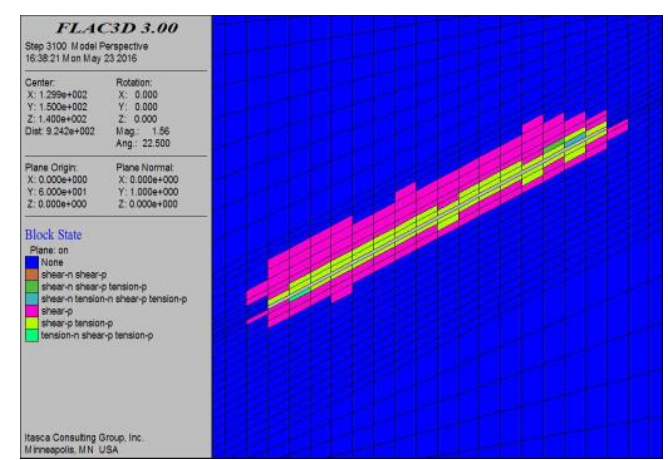

(a) The floor plastic zone

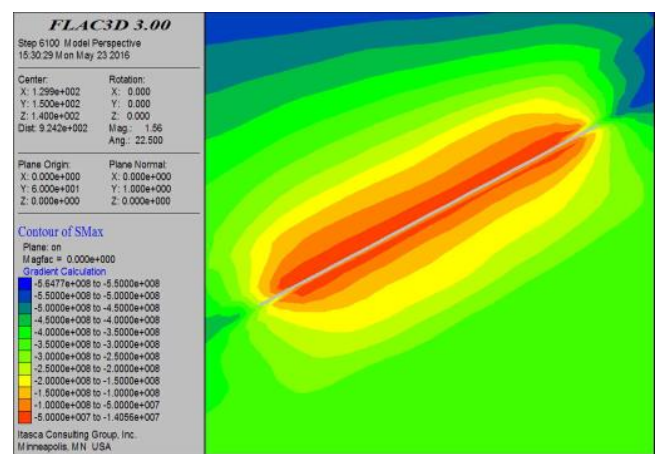

(b) The maximum principal stress

Fig.4 Distribution of plastic zone and maximum principal stress at $60 \mathrm{~m}$

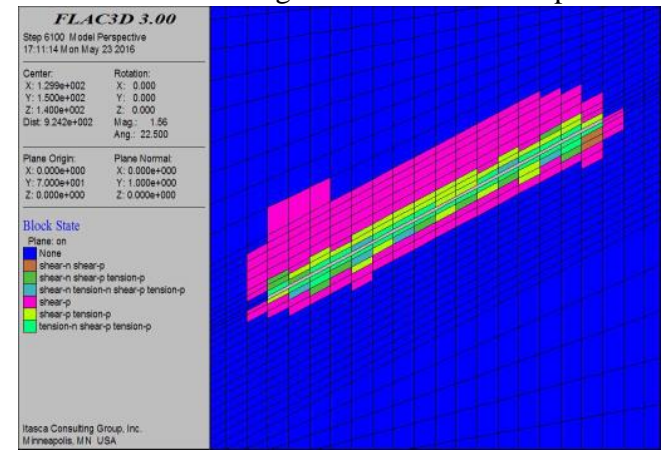

(a) The floor plastic zone

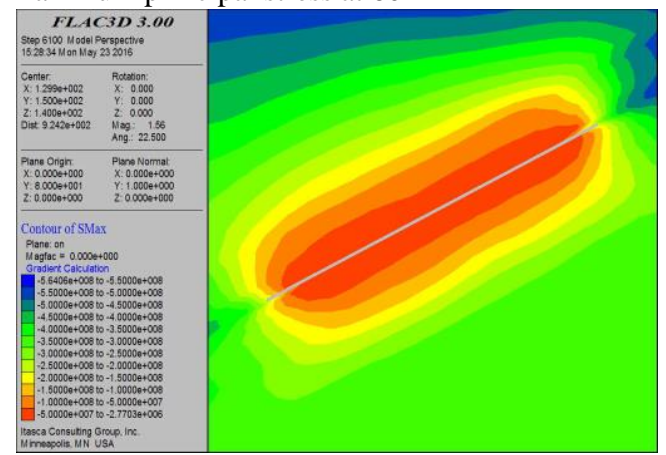

(b) The maximum principal stress

Fig.5 Distribution of plastic zone and maximum principal stress at $80 \mathrm{~m}$

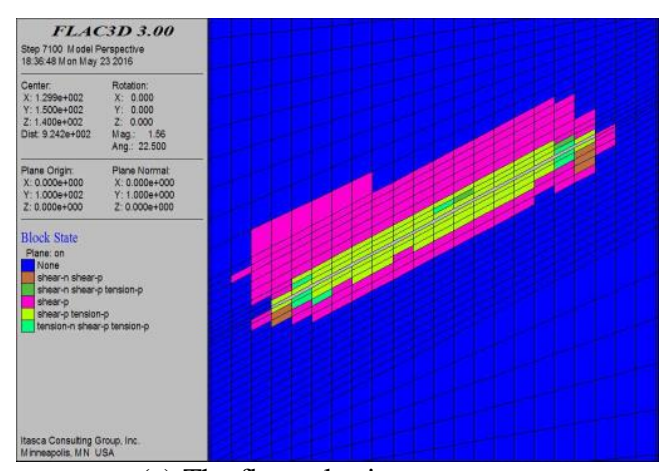

(a) The floor plastic zone

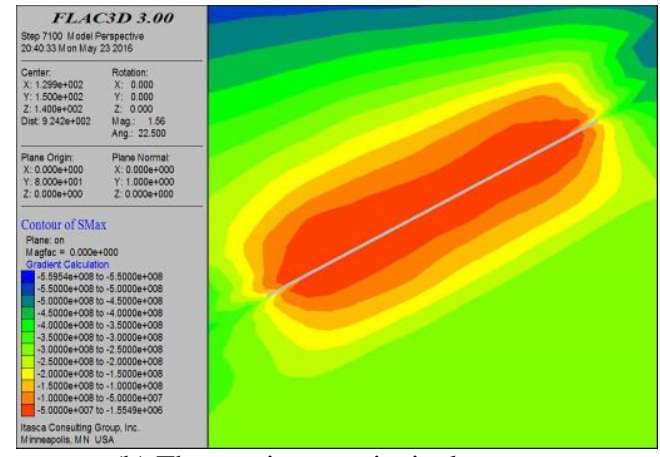

(b) The maximum principal stress

Fig.6 Distribution of plastic zone and maximum principal stress at $120 \mathrm{~m}$ 
From the slices of plastic zone and maximum principal stress of floor rock mass along 41303 working face when advancing $40 \mathrm{~m}, 60 \mathrm{~m}, 80 \mathrm{~m}$, and $120 \mathrm{~m}$, it can be seen:

With the working face advancing, the depth of floor damage is increasing continuously. When the working surface is pushed to $40 \mathrm{~m}$, the maximum damage depth of the floor is $4.25 \mathrm{~m}$; When the working surface is pushed to $60 \mathrm{~m}$, the maximum damage depth of the floor is $6.5 \mathrm{~m}$; When the working surface is pushed to $80 \mathrm{~m}$, the maximum damage depth of the floor is $10.75 \mathrm{~m}$; When the working surface is pushed to $120 \mathrm{~m}$, the maximum damage depth of the floor is $15 \mathrm{~m}$. The change trend of the maximum principal stress and the failure depth of the plastic zone in floor rock mass are roughly the same.

The plastic zone information of other slices in the model is summarized, as shown in figure 7. As

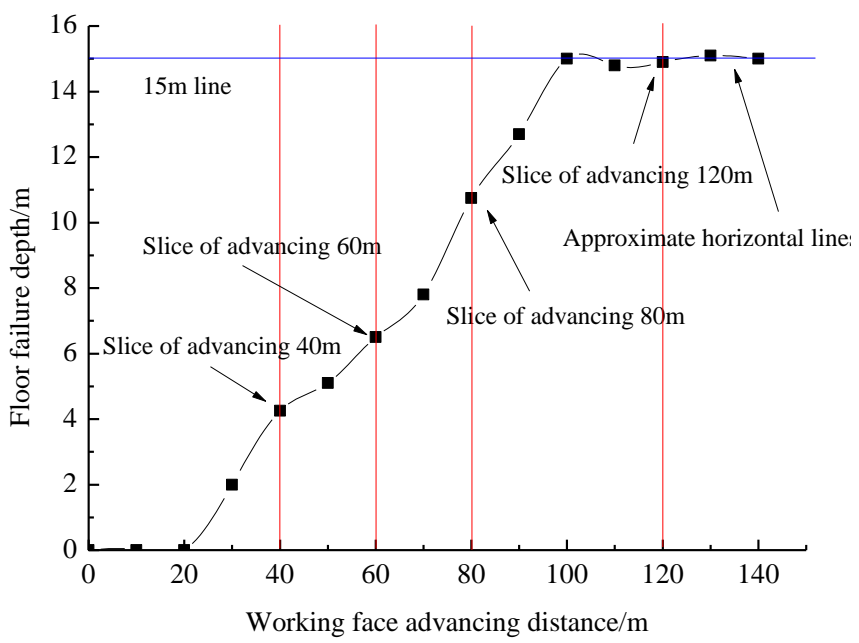

Fig.7 Floor damage depth trends

can be seen, when the working advancing100m, floor damage depth has reached $15 \mathrm{~m}$. As the working face continues to advance, the maximum damage depth is no longer increased and becomes a straight line which is approximately parallel to the bottom of the coal seam. Therefore, according to the FLAC $^{3 \mathrm{D}}$ numerical simulation, it can be obtained that the failure depth of floor mining is $15 \mathrm{~m}$.

\section{V.FIELD MEASUREMENT}

Measuring equipment and function

Double ends borehole plugging device belongs to test device for drilling permeability of rock mass in mine. It can be used for the water differential injection testing of drilling hole in floor rock mass at arbitrary azimuth and dip angle. According to the measurement of the water leakage in the hole section of different depth, the fracture development or surrounding rock failure condition is determined. Subsection water injection observation system mainly consists of four parts such as inner hole plugging water injection pipe, connecting pipe, external control valve and observation instruments, as shown in figure 8 . The inner hole plugging water injection pipe is a water injection probe with a double end sealing capsule, which is used for sealing the two ends of the test hole; The external control valve and observation instruments mainly include flow meter, pressure gauge and the corresponding valve, used to control the water injection pressure, sealing pressure and water injection flow rate.; The external control valve, instrument and water injection probe are connected with the high-pressure rubber hose and the pressure hose.

\section{VI.OBSERVATION SCHEME DESIGN}

The construction elements and requirements of the drilling hole design in the observation section are shown in table 2. According to construction elements and roadway conditions around the coal face, observation roadway and section was built near the lower coal pillar of 41303 haulageway. Before mining drilling is used to observe the original fracture state of floor rock mas which is the basis of comparative observation after the mining; After mining drilling is used to control maximum development depth of the mining failure zone of the floor strata. The layout of the borehole observation section is shown in Figure 9.

\section{VII.OBSERVATION RESULTS AND ANALYSIS}

According to the four measured data collected by before and after mining drill holes, making comparison and analysis of the leakage loss of drilling water injection changes with the drilling depth, and draw out the leakage loss diagram, as shown in Figure 10. 
drilling hole

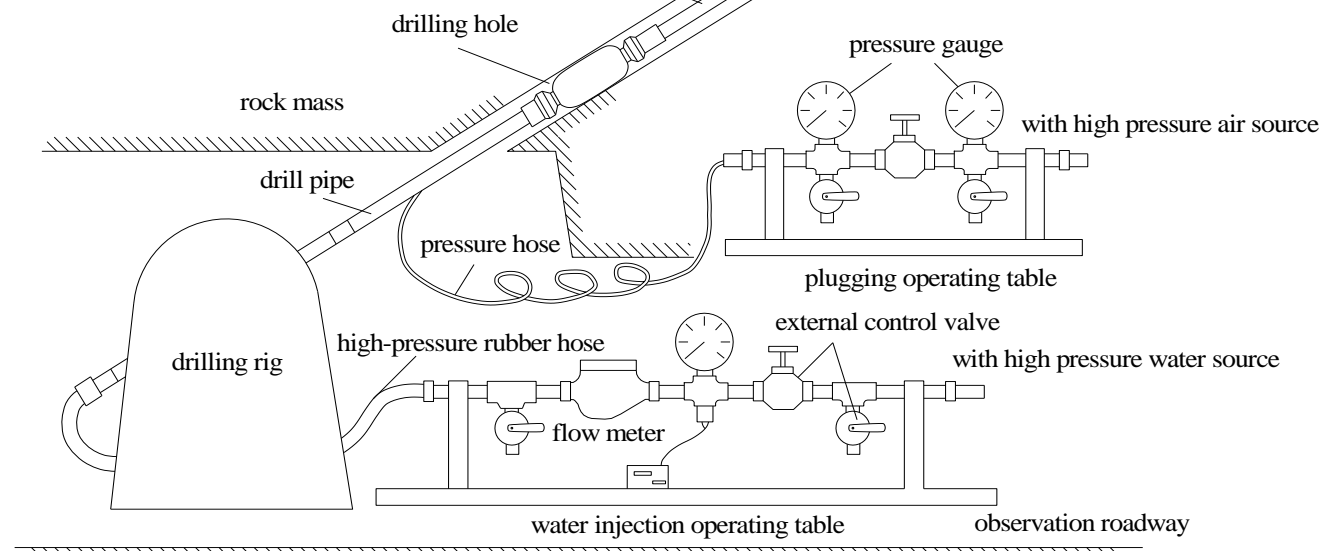

Fig.8 Double ends borehole plugging device in measuring leakage

Table 2 Drilling construction elements

\begin{tabular}{cccccc}
\hline Hole No. & Name & Aperture $/ \mathrm{mm}$ & Elevation $\left./{ }^{\circ}\right)$ & Hole depth/m & Complete time \\
\hline $1 \#$ & $\begin{array}{c}\text { Preharvest hole (Doubles as } \\
\text { a post-harvest hole) }\end{array}$ & 89 & $2^{\circ}$ & 60 & 5 days before mining \\
$2 \#$ & Post harvest hole & 89 & $8^{\circ}$ & 60 & When advancing $15 \mathrm{~m}$ \\
$3 \#$ & Post harvest hole & 89 & $15^{\circ}$ & 60 & When advancing $25 \mathrm{~m}$ \\
\hline
\end{tabular}

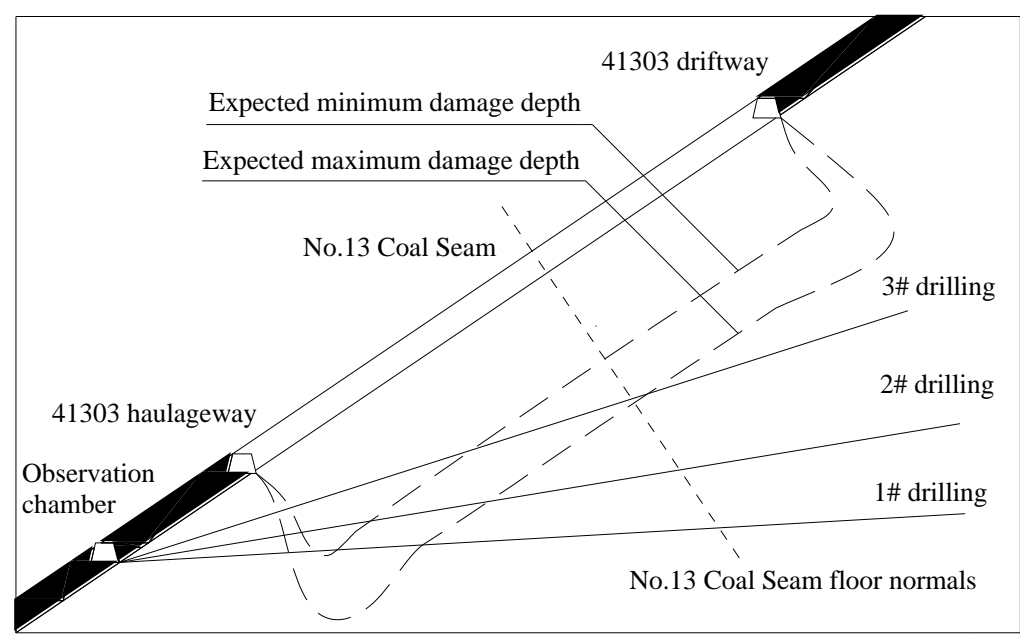

Fig.9 Drilling construction layout schematic diagram 


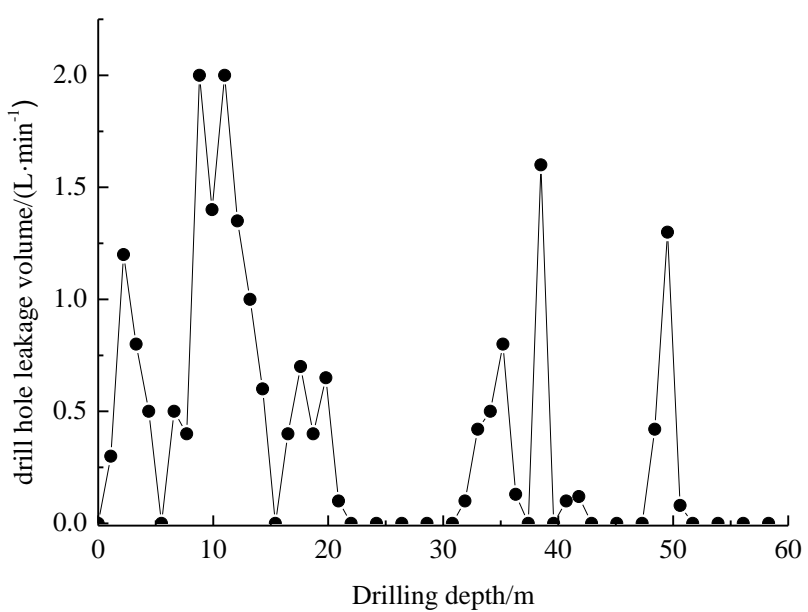

(a) Before mining drilling-No. $1^{\#}$

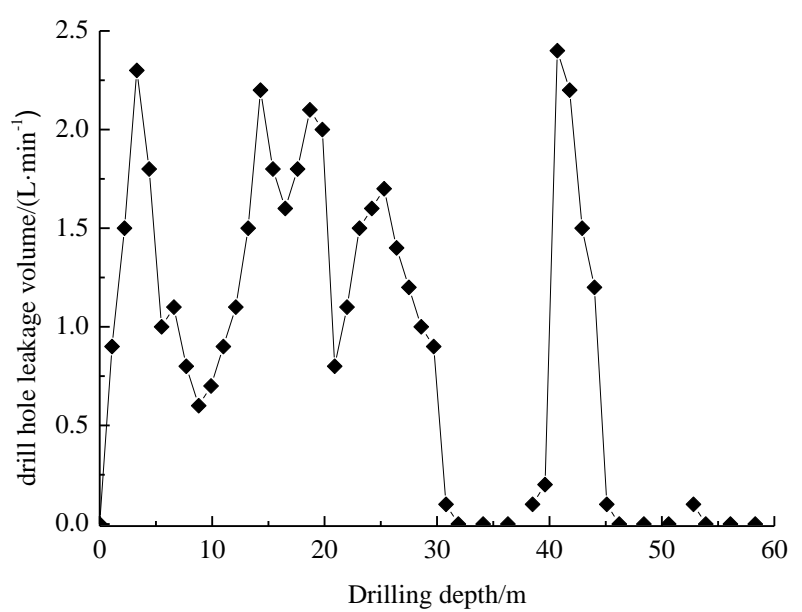

(c) After mining drilling-No. $2^{\#}$

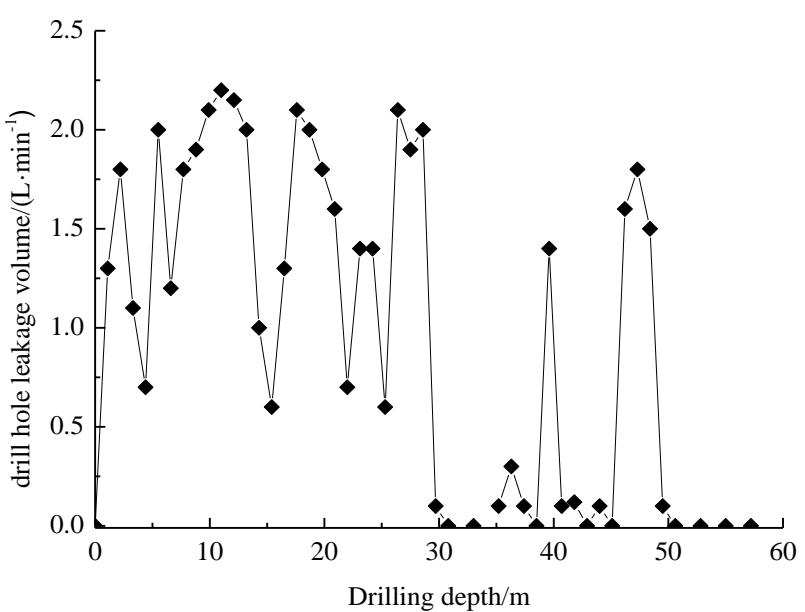

(b) After mining drilling-No. $1^{\text {\# }}$

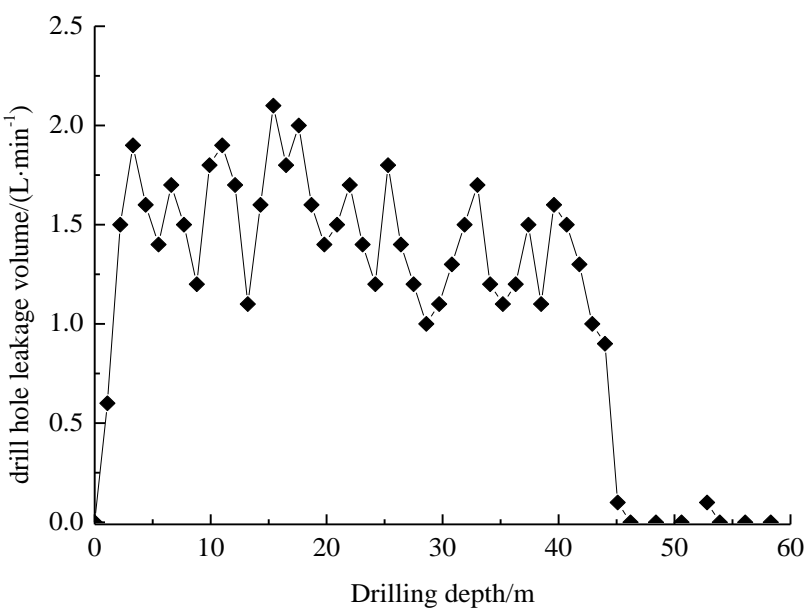

(d) After mining drilling-No. $3^{\#}$

Fig.10 Injected water leakage of drilling hole

(1) Through the before mining drilling No. $1^{\#}$, it can be seen that there is a clear water leakage point at the depth of $3 \mathrm{~m}$, and the leakage volume is about $1.2 \mathrm{~L} / \mathrm{min}^{-1}$. That is caused by the rock destruction of the shallow hole and the formation of the loose circle during drilling construction. At the depth $8 \sim 14 \mathrm{~m}$ and $17 \sim 20 \mathrm{~m}$, the leakage volume is significantly increased, $1.4 \sim 2.0 \mathrm{~L} / \mathrm{min}^{-1}$ and $0.5 \sim 0.8 \mathrm{~L} / \mathrm{min}^{-1}$, respectively. According to the numerical analysis of the leakage volume and floor lithology, it may be caused by the influence of tunnel excavation or the development of local primary fissures. At the depth $34 \mathrm{~m}, 39 \mathrm{~m}$ and $50 \mathrm{~m}$, the leakage volume is about $0.6 \sim 1.7 \mathrm{~L} \mathrm{~min} \mathrm{~m}^{-1}$, and the leakage volume of the other position of the hole tends to be close to 0 . It shows that the fracture of deep layer is not developed, and it is in a continuous and complete state.

(2) Because of the before mining hole No. $1^{\#}$ remaining in good condition, the field measurement using that as after mining hole were observed again. Through measured data, it can be seen that the original leakage volume of after mining hole is increased, and the leakage volume at shallow hole rock is increased from $1.2 \mathrm{~L} / \mathrm{min}^{-1}$ to $1.7 \mathrm{~L} / \mathrm{min}^{-1}$. Affected by mining, the original shallow primary fracture is further developed, and the corresponding leakage volume is also increased. At the depth of the hole $8 \sim 14 \mathrm{~m}, 17 \sim 20 \mathrm{~m}$ and $21 \sim 33 \mathrm{~m}$, the maximum leakage volume is increased from $2.0 \mathrm{~L}$ $/ \mathrm{min}^{-1}$ to $2.2 \mathrm{~L} / \mathrm{min}^{-1}, 0.8 \mathrm{~L} / \mathrm{min}^{-1}$ to $2.3 \mathrm{~L} / \mathrm{min}^{-1}$ and $2.2 \mathrm{~L} \cdot \mathrm{min}^{-1}$, respectively. At the depth of $21 \sim 33 \mathrm{~m}$, the original crack is further expanded into a new crack. The result shows that although there are few high value point of leakage volume at the deep position of the hole, the rock mass is generally kept intact.

Therefore, taking the depth $28 \mathrm{~m}$ of after mining hole No. $1^{\#}$ as the boundary of the depth of the floor failure depth, in accordance with the drilling angle of 2 degrees, the vertical failure depth of the floor is $13.15 \mathrm{~m}$.

(3) Through the after mining drilling No. $2^{\#}$, it can be seen that there is a continuous leakage volume of $\quad 0.7 \sim 1.7 \mathrm{~L} / \mathrm{min}^{-1}$ 
at the depth 20 30m. Compared with the leakage volume of before mining hole No. $1^{\#}$, it shows that this section is a new fracture. More than the depth $30 \mathrm{~m}$ of the hole ,there is only one continuous leakage points, which is not regarded as the development zone of fracture connectivity.

Therefore, taking the depth $30 \mathrm{~m}$ of after mining hole No. $2^{\#}$ as the boundary of the depth of the floor failure depth, in accordance with the drilling angle of 8 degrees, the vertical failure depth of the floor is $11.24 \mathrm{~m}$.

(4) Therefore, taking the depth $44 \mathrm{~m}$ of after mining hole No. $3^{\#}$ as the boundary of the depth of the floor failure depth, in accordance with the drilling angle of 15 degrees, the vertical failure depth of the floor is $11.39 \mathrm{~m}$. Due to the vertical distance between the after mining hole No. $3^{\#}$ and the bottom of the working face, this hole is most strongly affected by mining action. It can be seen from the leakage volume of drill, at the depth $0 \sim 44 \mathrm{~m}$, the leakage volume of drilling is greatly increased, and the average leakage volume is $1.6 \mathrm{~L} / \mathrm{min}^{-1}$. The cracks in the rock mass are fully penetrated. at the depth $44 \mathrm{~m} \sim 60 \mathrm{~m}$, the leakage volume is almost close to 0 .
In summary, the maximum damage depth of the 41303 working face in Huafeng coal mine is $13.15 \mathrm{~m}$.

\section{VIII.COMPREHENSIVE COMPARISON AND ANALYSIS OF TEST RESULTS}

Based on the geological conditions of 41303 working face in Huafeng coal mine, using the method of empirical formula, numerical simulation and field measurement, the numerical value of the failure depth of the floor is obtained. The theoretical prediction value is $16.89 \sim 21.24 \mathrm{~m}$, the numerical simulation result is $15 \mathrm{~m}$, and the field measured depth is $13.15 \mathrm{~m}$. The specific results obtained by comparing different methods and their advantages and disadvantages are shown in Table 3. It can be seen that the field measurement result is consistent with that of numerical simulation. And theoretical prediction is expected to consider the impact of limited factors. The result is conservative, and the expected value is too large. Comprehensive analysis shows that the failure depth of the floor of the 41303 working face is $13.15 \mathrm{~m}$, and the result is accurate and reliable.

Table 3 Methods and results analysis

\begin{tabular}{ccc}
\hline Method & Advantage & Shortcoming \\
Theoretical predictions & $\begin{array}{c}\text { Simple, reliable, easy to quickly } \\
\text { calculate }\end{array}$ & $\begin{array}{c}\text { Practical condition limitations, the results too } \\
\text { large }\end{array}$ \\
$\begin{array}{c}\text { FLAC } \\
\text { Simulation }\end{array}$ & $\begin{array}{c}\text { Low cost, high efficiency, better } \\
\text { reliability, simulate different geological } \\
\text { conditions }\end{array}$ & $\begin{array}{c}\text { Model complex process parameters can not be } \\
\text { fully representative of the actual conditions }\end{array}$ \\
$\begin{array}{c}\text { Double ends borehole plugging } \\
\text { device in measuring leakage }\end{array}$ & High accuracy, the most reliable results & $\begin{array}{c}\text { Heavy workload, complexity of operations, the } \\
\text { presence of measurement error }\end{array}$ \\
\hline
\end{tabular}

\section{IX.CONCLUSION}

(1) According to the geological conditions of 41303 working face in Huafeng coal mine, the theoretical prediction and numerical simulation are used to obtain the failure depth of the floor of the 41301 working face, which is $16.89 \sim 21.24 \mathrm{~m}$ and $15 \mathrm{~m}$;

(2) Using double plugging leakage detecting device to measure floor mining damage zones of 41303 working face and the result shows that the maximum failure depth of floor is $13.15 \mathrm{~m}$;

(3) By comparison, it can be seen that the numerical simulation results and are basically close to that of field measured. However, the result of empirical formula is tend to be conservative. After a comprehensive consideration, the maximum mining failure depth of the floor in41303 working face is $13.15 \mathrm{~m}$. It provides scientific basis for the safe mining of coal resources under the pressure of the confined water;

(4) With the advance of the working face, the floor failure range is continuously increasing. When the working face advances to $90 \mathrm{~m}$, floor mining failure depth has reached the maximum value of $15 \mathrm{~m}$, then the depth is not increased. The maximum depth is a straight line which is approximately parallel to the bottom of the coal seam. The change of plastic zone is consistent with the trend of the maximum principal stress.

\section{ACKNOWLEDGEMENT}

In this paper, the research was sponsored by the National Natural Science Foundation of China (Project No. 51274135), 
the Joint Research Fund for Overseas Natural Science of China (Project No. 51428401) and the State Key Program of

\section{REFERENCES}

[1] GUO Weijia, LIU Weitao, ZHANG Wenquan. Coal special mining [M]. Beijing: Coal Industry Publishing House, 2008: 145-147.

[2] LI Baiying, GUO Weijia. Mining damage and environment protection[M]. China Coal Industry Publishing House, 2004: 185-188.

[3] LI Baiying. Down three zones theory of the prevention of floor water inrush and its development and application[J]. Journal of Shandong Institute of Mining and Technology, 1999, 18(4): 11-18.

[4] WANG Zuoyu, LIU Hongquan. Limit analysis and calculation of hydraulic resistance of the remaining complete rock mass under floor[J]. Chinese Journal of Rock Mechanics and Engineering, 1994, 13(4): 319-326.

[5] WANG Zuoyu, LIU Hongquan, WANG Peiyi, et al. Coal mining discipline theory and practice above Confined water[J]. Journal of China Coal Society, 1994, 19(1): 40-48.

[6] LI Liangjie, YIN Youquan, QIAN Minggao. The structure stability of KS and water-inrush mechanism of floor strata[J]. Chinese Journal of Rock Mechanics and Engineering, 1998, 17(1): 40-45.

[7] SUN Jian, WANG Lianguo. Instability mechanics criterion of inclined water-resisting key strata in coal seam floor[J]. Journal of China Coal Society, 2014, 39(11): 2276-2285.

[8] SHI Longqing, XU Dongjing, QIU Mei, et al. Improved on the formula about the depth of damaged floor in working area[J]. Journal of China Coal Society, 2013, 38(增2): 299-303

[9] LU Haifeng, YAO Duoxi. Stress distribution and failure depths of layered rock mass of mining floor[J]. Chinese Journal of Rock Mechanics and Engineering, 2014, 33(10): 2030-2039.

[10] WANG Jinan, WEI Xianhao, CHEN Shaojie. Fracture and seepage characteristics in the floor strata when mining above a confined aquifer[J] Journal of China University of Mining \&Technology, 2012, 41(4): 536-542.

[11] JIANG Yaodong, LV Yukai,ZHAO Yixin, et al. Similar simulation test for breakage law of working face floor in coal mining above aquifer[J]. Chinese Journal of Rock Mechanics and Engineering, 2011 , 30(8): $1571-1578$.
National Natural Science of China (Project No. 51034003)

[12] LIU Weitao, LIU Shiliang. Mechanical analysis and numerical simulation on the mining failure depth of floor[J]. Mining R\&D, 2015, 35(10): 94-98

[13] LIU Weitao, LIU Shiliang, JI Baojing. Sensitivity analysis of controlling factors on failure depth of floor based on orthogonal experiment[J]. Journal of China Coal Society, 2015, 40(9): 1995-2001.

[14] LIU Weitao, WU Qiang. Numerical simulations of water inrush of fault F0 in fangezhuang coal mine [J]. Chinese Journal of Rock Mechanics and Engineering, 2008, 27(Suppl): 3604-3610

[15] ZHANG Rui, JIANG Zhenquan, YU Zongren, et al. Comprehensive testing and numerical analysis on the failure characteristics of mining coal seam floor[J]. Journal of Mining \& Safety Engineering, 2013, 30(4): 531-537.

[16] LIU Weitao, CAO Guangquan, SHEN Jianjun, et al. Field measurement and simulation research on floor failure depth[J]. Journal of Liaoning Technical University, 2013, 32(12): 1585-1588

[17] JIANG Fuxing, LIU Weijian, YE Genxi, et al. Coupling study of microseismic monitoring and numerical simulation for tectonic activation[J]. Chinese Journal of Rock Mechanics and Engineering, 2010, 29(Suppl): 3590-3597.

[18] ZHANG Pingsong, WU Jiwen, LIU Shengdong. Study on dynamic observation of coal seam floor's failure law[J]. Chinese Journal of Rock Mechanics and Engineering, 2006, 25(Suppl): 3009-3013.

[19] CHENG Xuefeng, LIU Shengdong, LIU Dengxian. Sound wave CT detecting of damage rule of surrounding rock after coal mining[J].Journal of China Coal Society, 2001, 26(2): 153-155.

[20] State Bureau of Coal Industry. Regulations of buildings, water,railway and main well laneleaving coal pillar and press coal mining[S]. Beijing: China Coal Industry Publishing House,2000: 235-236. 